\title{
Association between cyclin D1 (CCND1) G870A polymorphism and gastric cancer risk: a meta-analysis
}

\author{
Yafei Zhang ${ }^{1}$, Xianling Zeng ${ }^{2}$, Hongwei $\mathrm{Lu}^{1}$, Hong $\mathrm{Ji}^{1}$, Enfa $\mathrm{Zhao}^{3}$, Yiming $\mathrm{Li}^{1}$ \\ ${ }^{1}$ Department of General Surgery, Second Affiliated Hospital, School of Medicine, Xi'an Jiaotong University, Xi'an, Shaanxi, \\ China \\ ${ }^{2}$ Department of Obstetrics and Gynecology, First Affiliated Hospital, School of Medicine, Xi'an Jiaotong University, Xi'an, \\ Shaanxi, China \\ ${ }^{3}$ Department of Ultrasound, Second Affiliated Hospital, School of Medicine, Xi'an Jiaotong University, Xi'an, Shaanxi, China \\ Correspondence to: Yiming Li, email: liyimingdoc@163.com \\ Keywords: gastric cancer, cyclin D 1 (CCND1) G870A, polymorphism, meta-analysis \\ Received: October 30, $2015 \quad$ Accepted: July 14, $2016 \quad$ Published: September 06, 2016
}

\section{ABSTRACT}

Published data on the association between cyclin D1 (CCND1) G870A polymorphism and gastric cancer (GC) risk are inconclusive. Thus, we conducted a meta-analysis to evaluate the relationship between CCND1 G870A polymorphism and GC risk. We searched PubMed, EMBASE, Web of science and the Cochrane Library up to June 12, 2015 for relevant studies. Odds ratios (ORs) and 95\% confidence intervals (CIs) were used to estimate the strength of associations. Nine studies published from 2003 to 2014, with a total of 1813 cases and 2173 controls, were included in this meta-analysis. The pooled results showed that there was no association between CCND1 G870A polymorphism and GC risk in any genetic model. The subgroup analysis stratified by ethnicity showed an increased breast cancer risk in Caucasian based on heterozygote comparison (GA vs. GG: $O R=1.49,95 \% \mathrm{CI}=1.06-2.10, \mathrm{P}=0.02$ ). We found the same association in population based (PB) stratified analyses by Source of controls (AA vs. GG: OR=1.39, 95\% CI=1.01-1.93, 0.05). When stratifying by the type, Sex and $H$. pylori infection in dominant model, Interestingly, we found the opposite result in Male (AA + GA vs. GG: $O R=0.5,95 \% \mathrm{CI}=0.33-0.76, P=0.001$ ), there were no association between CCND1 G870A polymorphism and GC risk in any other subgroup. This meta-analysis suggests that CCND1 G870A polymorphism is a risk factor for susceptibility to GC in Caucasians and in general populations. While, CCND1 G870A polymorphism plays a possible protective effect in GC in Male. Further large scale multicenter epidemiological studies are warranted to confirm this finding.

\section{INTRODUCTION}

Gastric cancer(GC), one of the most frequently encountered malignant tumors, has become the third main reasons of tumor-associated death in our word, whose 5 -year survival rate is low, especially for advanced GC $[1,2]$. In most of non developed world, the incidence of GC is constantly increasing, as well as mortality $[3,4]$. For most GCs are diagnosed to be advanced stages, early detection seems particularly important [5]. While, the determination of the relationship between CCND1 G870A polymorphism and the occurrence of GC provides us an effective way to reach the goal.

As a kind of important proteins that regulate cell cycle, CCND1 is of important effect in the regulation of cell transformation from $\mathrm{G} 1$ phase to $\mathrm{S}$ phase $[6,7]$. In exon 4, CCND1 gene has a $\mathrm{G}>\mathrm{A}$ polymorphism (G870A), which makes mRNA to produce an alternative splice site, change the protein structure of the carboxy terminal domain, resulting the disorder in cell cycle regulation Checkpoint (G1/S), reduced the capacity of DNA repair $[8,9]$. Over expression of related proteins will accelerate the G1 phase, and promote the proliferation of cells, which may lead to cancer occurrence $[10,11]$.

Previous functional studies have reported the relationship between cyclin D1 G870A polymorphism and the occurrence of GC, However, the conclusions are still inconclusive [12-20]. To clarify this, Chen et al [21] made a comprehensive analysis of the associations between cyclin D1 G870A and digestive tract cancers. 
However, number of their studies included in their metaanalysis about GC is just four, and GC is just a small part of their study. In their subgroup studies, the sample size is extremely small. Therefore, we decided to carry out a meta-analysis on the whole included case-control researches to make a more accurate assessment of the relationship. Furthermore, we conducted several subgroup analyses stratified by ethnicity, source of controls, genotyping method, tumor type, Sex and H. pylori infection.

\section{RESULTS}

\section{Characteristics of eligible studies}

Detailed retrieval procedures are summarized in Figure 1. A total of 148 references were preliminarily identified at first based on our selection strategy. There were 28, 51, 68, 1 records in database of PubMed, EMBASE, Web of science and the Cochrane Library, respectively. 95 records left after excluding duplicate

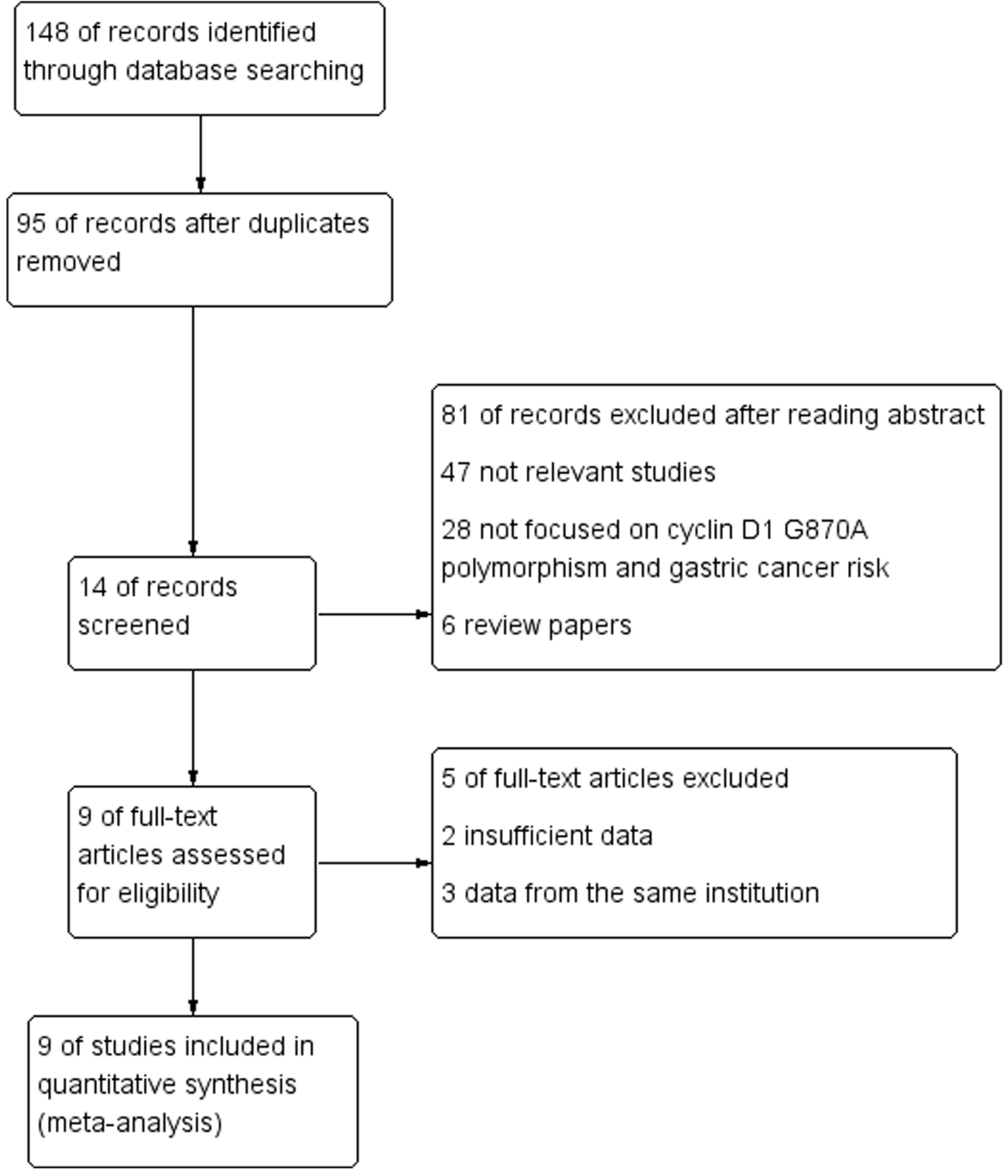

Figure 1: Flow chart of studies selection in this meta-analysis. 
Table 1: Characteristics of the studies included in the meta-analysis

\begin{tabular}{lcccccccc}
\hline First author & Year & Country & Ethnicity & $\begin{array}{c}\text { Study } \\
\text { design }\end{array}$ & $\begin{array}{c}\text { Source of } \\
\text { controls }\end{array}$ & $\begin{array}{c}\text { Genotyping } \\
\text { method }\end{array}$ & $\begin{array}{c}\text { Number(case/ } \\
\text { control) }\end{array}$ & HWE \\
\hline Zhang et al [12] & 2003 & China & Asian & CC & PB & PCR-SSCP & $87 / 183$ & 0.117904 \\
Kiel et al [16] & 2004 & Germany & Caucasian & CC & PB & PCR-RFLP & $106 / 245$ & 0.216215 \\
Geddert et al [18] & 2005 & Germany & Caucasian & CC & HB & PCR-RFLP & $286 / 253$ & 0.223914 \\
Song et al [14] & 2007 & Korea & Asian & CC & NR & PCR-SSCP & $253 / 442$ & 0.623066 \\
Jia et al [17] & 2008 & China & Asian & CC & HB & PCR-RFLP & $159 / 162$ & 0.080933 \\
Fang et al [19] & 2013 & China & Asian & CC & HB & PCR-RFLP & $115 / 112$ & 0.2067 \\
Tahara et al [13] & 2009 & Japan & Asian & CC & HB & PCR-RFLP & $392 / 359$ & 0.923934 \\
Bukum et al [20] & 2013 & Turkey & Asian & CC & PB & PCR-RFLP & $57 / 59$ & 0.634847 \\
Kuo et al [15] & 2014 & China & Asian & CC & PB & PCR-RFLP & $358 / 358$ & 0.000288 \\
\hline
\end{tabular}

HWE: Hardy-Weinberg equilibrium; CC: case-control; PB: population based; HB: hospital-based; NR: not reported; PCR: polymerase chain reaction; RFLP: restriction fragment length polymorphism; SSCP: Single Strand Conformation Polymorphism;

articles. We reviewed titles and abstracts of all identified studies and excluded 47 papers that were clearly irrelevant, 28 studies that not focused on CCND1 G870A polymorphism and the occurrence of GC, 6 records that were review papers. Next, the whole of the rest of the papers were examined according to the inclusion and exclusion criteria. 5 of full-text articles excluded for 2 insufficient data and 3 data from the same institution. Finally, 9 studies about cyclin D1 G870A polymorphism and GC risk were eventually included in our study, including 1813 cases and 2173 controls. Characteristics of eligible analyses are shown in Table 1 . The 9 casecontrol papers were published between 2003 and 2014, among them, 2 studies were performed in Caucasians and 7 in Asians. Four studies were hospital-based, four were population-based and one not reported.

\section{Meta-analysis results}

The Cyclin D1 (G870A) polymorphisms genotype distribution and allele frequency in cases and controls were listed in Table 2. The main results of our study were shown in Table 3 and 4. A total of 9 studies with 1813 cases and 2173 controls were included. As show in Table 3, The pooled results indicated that there was not any relationships between G870A polymorphism and the occurrence of GC in any genetic model: Allele model ( $\mathrm{OR}=1.07,95 \% \mathrm{CI}=0.88-1.30, \mathrm{P}=0.51)$, dominant model $(\mathrm{OR}=1.07,95 \% \mathrm{CI}=0.81-1.41, \mathrm{P}=0.65)$ recessive model $(\mathrm{OR}=1.09,95 \% \mathrm{CI}=0.80-1.49, \mathrm{P}=0.58)$ homozygous genetic model $(\mathrm{OR}=1.09,95 \% \mathrm{CI}=0.73-1.63, \mathrm{P}=0.66)$ heterozygote comparison $(\mathrm{OR}=1.03,95 \% \mathrm{CI}=0.80-1.32$, $\mathrm{P}=0.81$ ). The subgroup analysis stratified by ethnicity showed an increased GC risk in Caucasian based on heterozygote comparison (Figure 2, OR $=1.49,95 \%$ $\mathrm{CI}=1.06-2.10, \mathrm{P}=0.02$ ). while, there was not any genetic models attained statistical correlation in Asians (Table 3). We found an increased GC risk in population based (PB) stratified analyses by Source of controls (Figure 3, homozygous genetic model: $\mathrm{OR}=1.39,95 \% \mathrm{CI}=1.01-1.93$, $0.05)$. However, no statistically significant association in hospital-based (HB) (Table 3). When stratifying by the type, Sex and H. pylori infection in dominant model, Interestingly, we found the opposite result in Male (Figure 4, dominant model: $\mathrm{OR}=0.5,95 \% \mathrm{CI}=0.33-0.76$, $\mathrm{P}=0.001)$. While, not any relationships between CCND1 G870A polymorphism and GC risk in any other subgroups (Table 4).

\section{Sensitivity analyses}

As shown in Table 1, all the studies conformed to the balance of HWE in controls except Kuo's $(\mathrm{P}<0.05)$, however, after performing the sensitivity analyses, When removing any of the articles, the overall outcomes were no statistically significant change, suggesting that this metaanalysis has good stability and reliability.

\section{Detection for heterogeneity}

Heterogeneity among studies was obtained by Q statistic in the following genetic models: allele model $\left(\mathrm{P}<0.0001, \mathrm{I}^{2}=77 \%\right)$, the dominant model $(\mathrm{P}=0.003$, $\left.\mathrm{I}^{2}=66 \%\right)$, the recessive model $\left(\mathrm{P}<0.0001, \mathrm{I}^{2}=76 \%\right)$, the homozygous genetic model $\left(\mathrm{P}<0.0001, \mathrm{I}^{2}=75 \%\right)$, and the heterozygous genetic model $\left(\mathrm{P}=0.04, \mathrm{I}^{2}=52 \%\right)$, the random-effects model was applied in these studies.

\section{Publication bias}

We use Begg's funnel plot and Egger test to evaluate the published bias. As shown in Figure 5, the funnel plot 
Table 2: Cyclin D1 (G870A) polymorphisms genotype distribution and allele frequency in cases and controls

\begin{tabular}{|c|c|c|c|c|c|c|c|c|c|c|c|c|}
\hline \multirow{3}{*}{ First author } & \multicolumn{8}{|c|}{ Genotype (N) } & \multicolumn{4}{|c|}{ Allele frequency $(\mathbf{N})$} \\
\hline & \multicolumn{4}{|c|}{ Case } & \multicolumn{4}{|c|}{ Control } & \multicolumn{2}{|c|}{ Case } & \multicolumn{2}{|c|}{ Control } \\
\hline & Total & GG & GA & $\mathbf{A A}$ & Total & GG & GA & $\mathbf{A A}$ & $\mathbf{G}$ & $\mathbf{A}$ & G & $\mathbf{A}$ \\
\hline Zhang et al [12] & 87 & 19 & 40 & 28 & 183 & 38 & 102 & 43 & 78 & 96 & 178 & 188 \\
\hline Kiel et al [16] & 106 & 22 & 64 & 20 & 245 & 61 & 132 & 52 & 108 & 104 & 254 & 236 \\
\hline Geddert et al [18] & 286 & 55 & 188 & 43 & 253 & 63 & 136 & 54 & 298 & 274 & 262 & 244 \\
\hline Song et al [14] & 253 & 71 & 125 & 57 & 442 & 102 & 226 & 114 & 267 & 239 & 430 & 454 \\
\hline Jia et al [17] & 159 & 31 & 81 & 47 & 162 & 16 & 85 & 61 & 143 & 175 & 117 & 207 \\
\hline Fang et al [19] & 115 & 17 & 46 & 52 & 112 & 36 & 49 & 27 & 80 & 150 & 121 & 103 \\
\hline Tahara et al [13] & 392 & 98 & 197 & 97 & 359 & 98 & 180 & 81 & 393 & 391 & 376 & 342 \\
\hline Bukum et al [20] & 57 & 16 & 28 & 13 & 59 & 11 & 31 & 17 & 60 & 54 & 53 & 65 \\
\hline Kuo et al [15] & 358 & 46 & 178 & 134 & 358 & 59 & 212 & 87 & 270 & 446 & 330 & 386 \\
\hline
\end{tabular}

Table 3: Meta-analysis results

\begin{tabular}{|c|c|c|c|c|c|c|c|}
\hline \multirow{2}{*}{ subgroup } & & \multirow[b]{2}{*}{ OR } & \multirow[b]{2}{*}{$95 \% \mathrm{CI}$} & \multirow[b]{2}{*}{ P value } & \multicolumn{2}{|c|}{ Heterogeneity } & \multirow[b]{2}{*}{ Effects model } \\
\hline & & & & & $\mathbf{I}^{2}$ & P value & \\
\hline \multicolumn{8}{|l|}{ A vs. G } \\
\hline Overall & & 1.07 & $0.88-1.30$ & 0.51 & $77 \%$ & $<0.0001$ & $\mathrm{R}$ \\
\hline \multirow[t]{2}{*}{ Ethnicity } & Caucasian & 1 & $0.83-1.22$ & 0.96 & $0 \%$ & 0.81 & $\mathrm{~F}$ \\
\hline & Asian & 1.09 & $0.84-1.41$ & 0.53 & $83 \%$ & $<0.0001$ & $\mathrm{R}$ \\
\hline \multirow[t]{2}{*}{ Source of controls } & PB & 1.13 & $0.88-1.44$ & 0.34 & $54 \%$ & 0.09 & $\mathrm{R}$ \\
\hline & $\mathrm{HB}$ & 1.12 & $0.77-1.61$ & 0.56 & $86 \%$ & $<0.0001$ & $\mathrm{R}$ \\
\hline \multirow[t]{2}{*}{ Genotyping method, } & PCR-SSCP & 0.92 & $0.77-1.11$ & 0.40 & $54 \%$ & 0.14 & $\mathrm{~F}$ \\
\hline & PCR-RFLP & 1.10 & 0.86 & 1.40 & $80 \%$ & $<0.0001$ & $\mathrm{R}$ \\
\hline \multicolumn{8}{|l|}{$\mathrm{AA}+\mathrm{GA}$ vs. GG } \\
\hline Overall & & 1.07 & $0.81-1.41$ & 0.65 & $66 \%$ & 0.003 & $\mathrm{R}$ \\
\hline \multirow[t]{2}{*}{ Ethnicity } & Caucasian & 1.35 & $0.97-1.87$ & 0.08 & $0 \%$ & 0.79 & $\mathrm{~F}$ \\
\hline & Asian & 0.99 & $0.70-1.41$ & 0.96 & $71 \%$ & 0.002 & $\mathrm{R}$ \\
\hline \multirow[t]{2}{*}{ Source of controls } & PB & 1.13 & $0.86-1.49$ & 0.39 & $9 \%$ & 0.35 & $\mathrm{~F}$ \\
\hline & $\mathrm{HB}$ & 1.19 & $0.69-2.05$ & 0.54 & $81 \%$ & 0.001 & $\mathrm{R}$ \\
\hline \multirow[t]{2}{*}{ Genotyping method, } & PCR-SSCP & 0.81 & $0.59-1.10$ & 0.17 & $0 \%$ & 0.59 & $\mathrm{~F}$ \\
\hline & PCR-RFLP & 1.15 & $0.82-1.61$ & 0.42 & $67 \%$ & 0.005 & $\mathrm{R}$ \\
\hline \multicolumn{8}{|l|}{$\mathrm{AA}$ vs. $\mathrm{GA}+\mathrm{GG}$} \\
\hline Overall & & 1.09 & $0.80-1.49$ & 0.58 & $76 \%$ & $<0.0001$ & $\mathrm{R}$ \\
\hline \multirow[t]{2}{*}{ Ethnicity } & Caucasian & 0.72 & $0.51-1.03$ & 0.07 & $0 \%$ & 0.45 & $\mathrm{~F}$ \\
\hline & Asian & 1.22 & $0.86-1.73$ & 0.28 & $76 \%$ & 0.0003 & $\mathrm{R}$ \\
\hline \multirow[t]{2}{*}{ Source of controls } & PB & 1.26 & $0.81-1.96$ & 0.31 & $63 \%$ & 0.04 & $\mathrm{R}$ \\
\hline & HB & 1.05 & $0.62-1.79$ & 0.85 & $83 \%$ & 0.0006 & $\mathrm{R}$ \\
\hline
\end{tabular}




\begin{tabular}{|c|c|c|c|c|c|c|c|}
\hline \multirow{2}{*}{ subgroup } & & \multirow[b]{2}{*}{ OR } & \multirow[b]{2}{*}{$95 \%$ CI } & \multirow[b]{2}{*}{ P value } & \multicolumn{2}{|c|}{ Heterogeneity } & \multirow[b]{2}{*}{ Effects model } \\
\hline & & & & & $\mathbf{I}^{2}$ & P value & \\
\hline \multirow[t]{2}{*}{ Genotyping method, } & PCR-SSCP & 1.09 & $0.60-1.98$ & 0.77 & $69 \%$ & 0.07 & $\mathrm{R}$ \\
\hline & PCR-RFLP & 1.09 & $0.74-1.60$ & 0.68 & $80 \%$ & 0.0001 & $\mathrm{R}$ \\
\hline \multicolumn{8}{|l|}{ AA vs. GG } \\
\hline Overall & & 1.09 & $0.73-1.63$ & 0.66 & $75 \%$ & $<0.0001$ & $\mathrm{R}$ \\
\hline \multirow[t]{2}{*}{ Ethnicity } & Caucasian & 0.97 & $0.63-1.48$ & 0.87 & $0 \%$ & 0.73 & $\mathrm{~F}$ \\
\hline & Asian & 1.12 & $0.67-1.87$ & 0.66 & $81 \%$ & $<0.0001$ & $\mathrm{R}$ \\
\hline \multirow[t]{2}{*}{ Source of controls } & PB & 1.39 & 1.01-1.93 & 0.05 & $50 \%$ & 0.11 & $\mathbf{F}$ \\
\hline & HB & 1.14 & $0.54-2.44$ & 0.73 & $85 \%$ & 0.0001 & $\mathrm{R}$ \\
\hline \multirow[t]{2}{*}{ Genotyping method, } & PCR-SSCP & 0.84 & $0.58-1.23$ & 0.37 & $47 \%$ & 0.17 & $\mathrm{~F}$ \\
\hline & PCR-RFLP & 1.14 & $0.70-1.87$ & 0.60 & $78 \%$ & 0.0001 & $\mathrm{R}$ \\
\hline \multicolumn{8}{|l|}{ GA vs. GG } \\
\hline Overall & & 1.03 & $0.80-1.32$ & 0.81 & $52 \%$ & 0.04 & $\mathrm{R}$ \\
\hline \multirow[t]{2}{*}{ Ethnicity } & Caucasian & 1.49 & $1.06-2.10$ & 0.02 & $0 \%$ & 0.65 & $\mathbf{F}$ \\
\hline & Asian & 0.92 & $0.70-1.21$ & 0.56 & $45 \%$ & 0.09 & $\mathrm{R}$ \\
\hline \multirow[t]{2}{*}{ Source of controls } & $\mathrm{PB}$ & 1.02 & $0.76-1.36$ & 0.90 & $0 \%$ & 0.44 & $\mathrm{~F}$ \\
\hline & HB & 1.16 & $0.72-1.87$ & 0.54 & $72 \%$ & 0.01 & $\mathrm{R}$ \\
\hline \multirow[t]{2}{*}{ Genotyping method, } & PCR-SSCP & 0.79 & $0.57-1.10$ & 0.16 & $0 \%$ & 0.97 & $\mathrm{~F}$ \\
\hline & PCR-RFLP & 1.12 & $0.83-1.50$ & 0.45 & $53 \%$ & 0.05 & $\mathrm{R}$ \\
\hline
\end{tabular}

F-fixed effects model; R-random effects model.

Table 4: Association between cyclin D1 (CCND1) G870A polymorphism and type, Sex and H. pylori infection of the gastric cancer patients based on dominant models

\begin{tabular}{|c|c|c|c|c|c|c|c|}
\hline \multirow{3}{*}{$\begin{array}{l}\text { Subgroup } \\
\text { analyses }\end{array}$} & \multicolumn{7}{|c|}{ AA + GA vs. GG } \\
\hline & \multicolumn{7}{|c|}{ Heterogeneity } \\
\hline & OR & $95 \% \mathrm{CI}$ & P value & $\mathbf{I}^{2}$ & P value & Effects model & No. of studies \\
\hline \multicolumn{8}{|l|}{ Type } \\
\hline cardiac & 0.9 & $0.60-1.36$ & 0.63 & $0 \%$ & 0.88 & $\mathrm{~F}$ & 2 \\
\hline non-cardiac & 1.33 & $0.49-3.59$ & 0.58 & $88 \%$ & 0.0002 & $\mathrm{R}$ & 3 \\
\hline \multicolumn{8}{|l|}{ Sex } \\
\hline Male & 0.5 & $0.33-0.76$ & 0.001 & $0 \%$ & 0.75 & $\mathbf{F}$ & 2 \\
\hline Female & 0.79 & $0.28-2.23$ & 0.66 & $71 \%$ & 0.07 & $\mathrm{R}$ & 2 \\
\hline \multicolumn{8}{|c|}{ H. pylori infection } \\
\hline Positive & 1.15 & $0.16-8.09$ & 0.89 & $92 \%$ & 0.0005 & $\mathrm{R}$ & 2 \\
\hline Negative & 1.16 & $0.53-2.56$ & 0.71 & $57 \%$ & 0.13 & $\mathrm{~F}$ & 2 \\
\hline
\end{tabular}




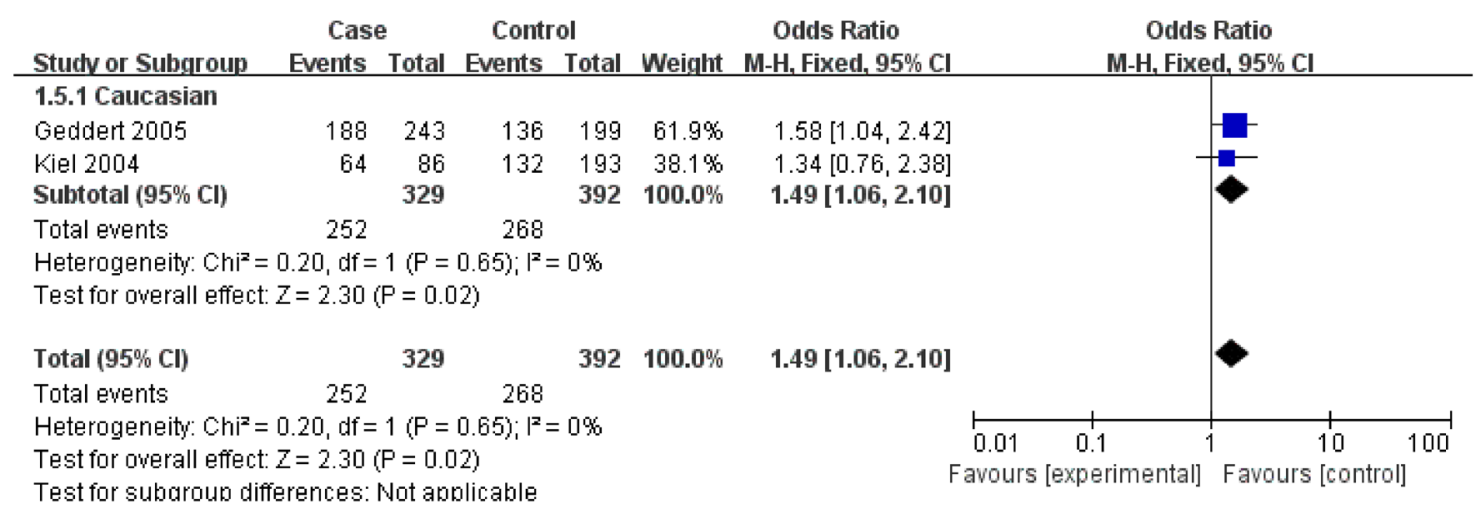

Figure 2: Forest plots of the cyclin D1 (CCND1) G870A polymorphism and gastric cancer risk in the Caucasian subgroup (GA vs. GG).

Notes: The squares and horizontal lines correspond to the study specific OR and $95 \%$ CI. The area of the squares reflects the weight (inverse of the variance). The diamond represents the summary OR and $95 \% \mathrm{CI}$.

Abbreviations: CI, confidence interval; OR, odds ratio; df, degrees of freedom; M-h, Mantel-haenszel.

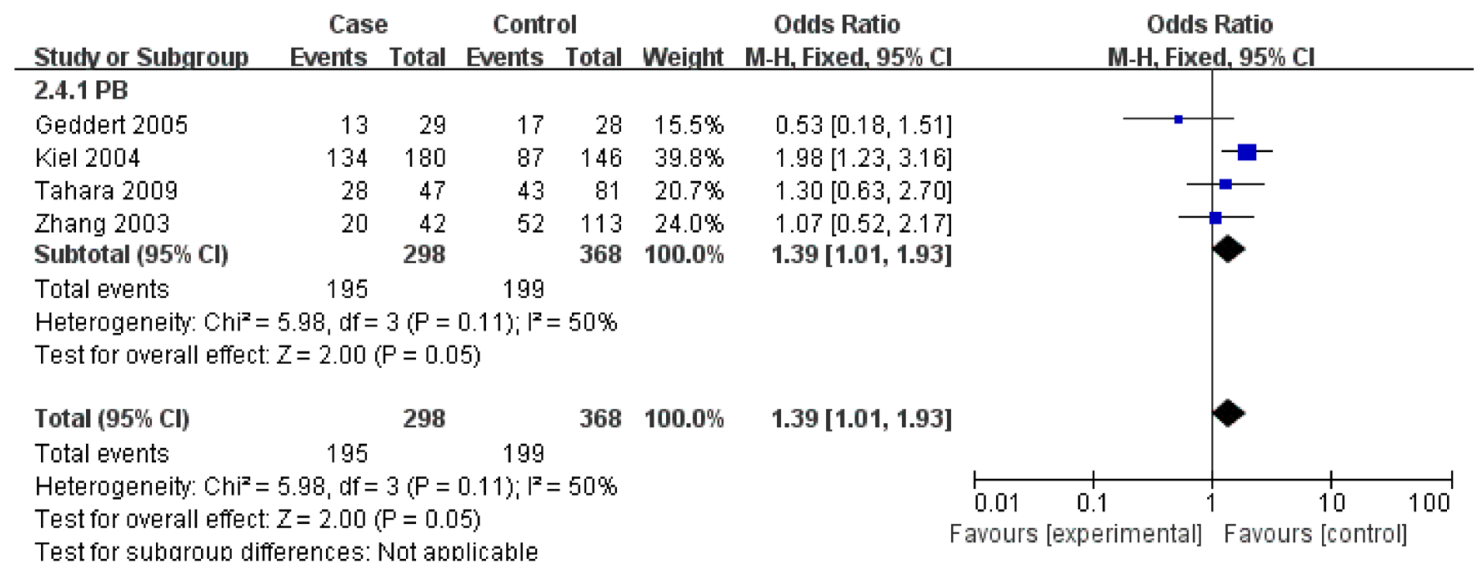

Figure 3: Forest plots of the cyclin D1 (CCND1) G870A polymorphism and gastric cancer risk in the population based (PB) subgroup (AA vs. GG).

Abbreviations: CI, confidence interval; OR, odds ratio; df, degrees of freedom; M-h, Mantel-haenszel.

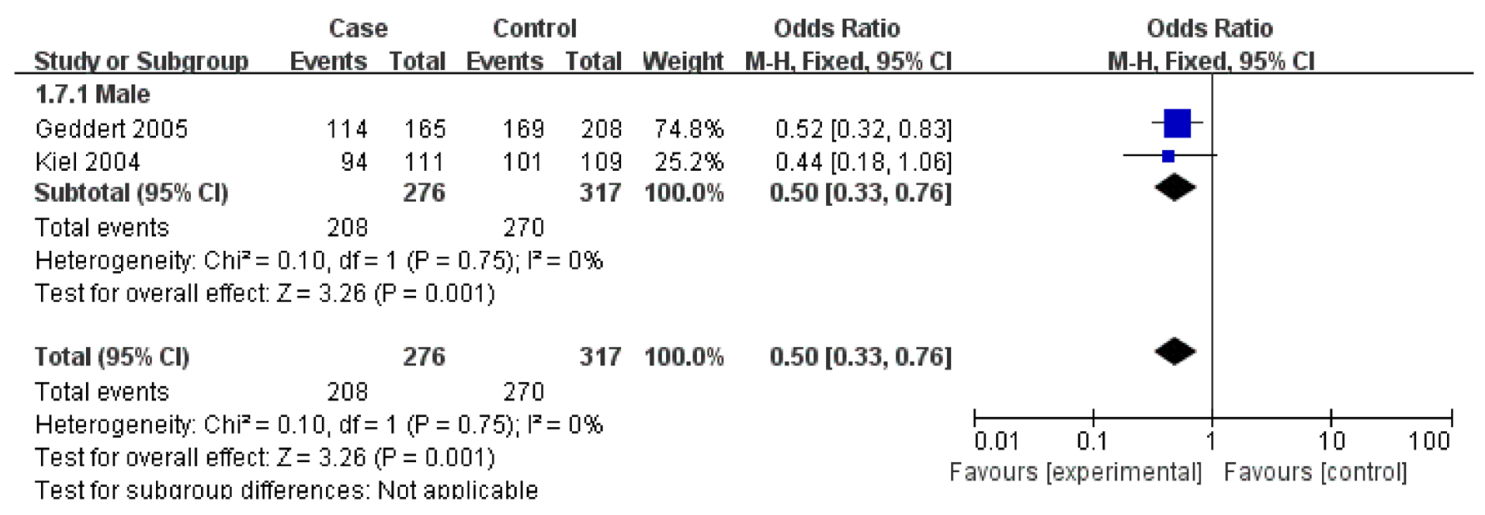

Figure 4: Forest plots of the cyclin D1 (CCND1) G870A polymorphism and gastric cancer risk in the Male subgroup (AA + GA vs. GG).

Abbreviations: CI, confidence interval; OR, odds ratio; df, degrees of freedom; M-h, Mantel-haenszel. 
is symmetrical, indicating that there is no significant publication bias in the total population. In our metaanalysis, no significant publication bias was found in the Begg's test and Egger's test $(\mathrm{P}>0.05)$.

\section{DISCUSSION}

CCND1 alterations was reported to be frequently seen in GC and associated with its poor differentiation $[22,23]$. The CCND1 polymorphism is a much concerned Single Nucleotide Polymorphism (SNP), for the G870A allele creates a variant splice transcript popular as "transcript b" by regulating mRNA [24-27]. Transcript $\mathrm{b}$ is constitutively nuclear in localization and may be more oncogene [28-30]. Previous functional studies have reported the relationship between cyclin D1 G870A polymorphism and the occurrence of GC, However, the conclusions are still inconclusive $[21,31]$. Therefore, we carried out the meta-analysis on the whole included casecontrol researches to make a more accurate assessment of the relationship.

In our study, 9 studies were eventually included in our study, including 1813 cases and 2173 controls. [1220]. In the total population, the pooled results indicated that there was not any relationships between G870A polymorphism and the occurrence of $\mathrm{GC}$ in any genetic model: Allele model $(\mathrm{OR}=1.07,95 \% \mathrm{CI}=0.88-1.30$,
$\mathrm{P}=0.51)$, dominant model $(\mathrm{OR}=1.07,95 \% \mathrm{CI}=0.81-1.41$, $\mathrm{P}=0.65)$, recessive model $(\mathrm{OR}=1.09$, 95\% $\mathrm{CI}=0.80$ $1.49, \mathrm{P}=0.58)$, homozygous genetic model $(\mathrm{OR}=1.09$, $95 \% \mathrm{CI}=0.73-1.63, \mathrm{P}=0.66)$, heterozygote comparison $(\mathrm{OR}=1.03,95 \% \mathrm{CI}=0.80-1.32, \mathrm{P}=0.81)$.

The subgroup study stratified by ethnicity showed an increased GC risk in Caucasian based on heterozygote comparison. while, there was not any genetic models attained statistical correlation in Asians (Table 3). We found an increased GC risk in population based (PB) stratified analyses by Source of controls (Figure 3). However, no statistically significant association in hospital-based (HB) (Table 3). When stratifying by the type, Sex and H. pylori infection in dominant model, Interestingly, we found the opposite result in Male (Figure 4). While, not any relationships between CCND1 G870A polymorphism and GC risk in any other subgroups (Table 4).

In a previous meta-analysis by Chen et al [21], they found the cyclin D1 G870A allele can significantly promote the risk of GC in Caucasian based on heterozygote comparison which consistent with our findings. They also find the same risk in Males which was contrary to our findings. They also found the cyclin D1 G870A allele can significantly promote the risk of GC for population with $\mathrm{H}$. pylori infection, which was not shown in our studies. It should be pointed out that our results are

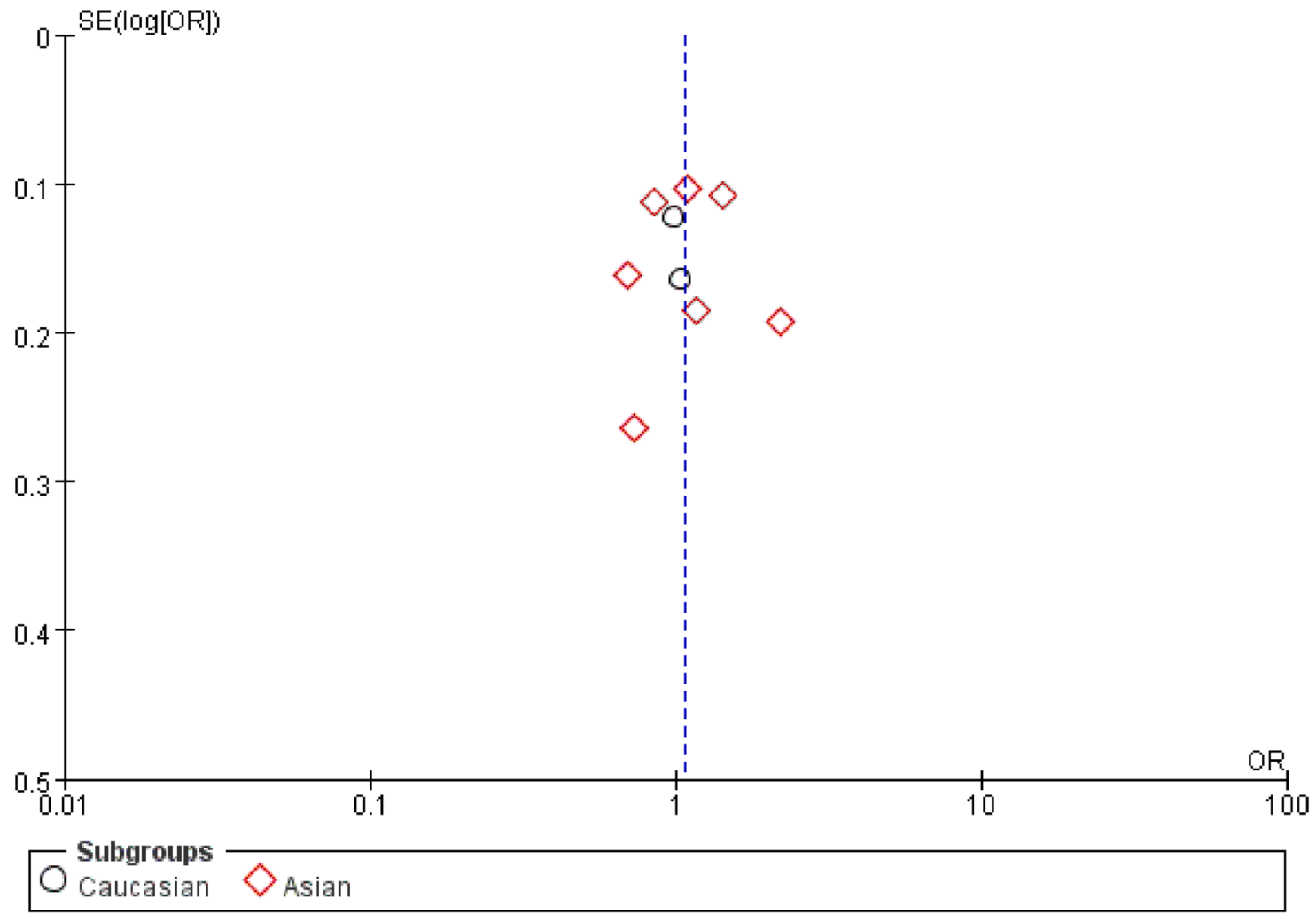

Figure 5: Funnel plot assessing evidence of publication bias from 9 studies (A vs. G). Abbreviations: SE, standard error; OR, odds ratio; A vs. G, Allele model. 
different from Chen's analysis. The contradiction may be due to the difference in the sample size and the differences in race. Only four papers were included in Chen's metaanalysis, while nine studies in our analysis.

Our meta-analysis has some limitations in the following aspects. First, Our study is a summary of the data. We did not verify it from the level of basic experiments. Second, We just included the published studies in our study. There may still be some published studies in line with the conditions. Third, the Selected papers were mostly from Asian population. Only two papers are about Caucasian population. Finally, just dominant model was used when stratifying by the type, Sex and H. pylori infection for the limitation of data. Data from a large sample of multiple centers based on Caucasian or African is still needed to confirm the relationship between cyclin D1 G870A polymorphism and $\mathrm{GC}$ risk.

In conclusion, our study suggests that CCND1 G870A polymorphism could increases the risk of GC in Caucasians and in general populations. While, CCND1 G870A polymorphism plays a possible protective role in GC among males. Data from a large sample of multiple centers is still needed to confirm our findings.

\section{MATERIALS AND METHODS}

\section{Literature searching strategy}

We searched PubMed, EMBASE, Web of science, the Cochrane Library for relevant studies published before June 12, 2015. The following keywords were used: CCND1/cyclin D1, variant/genotype/polymorphism/SNP, Gastric/stomach/cardia, cancer/carcinom*/neoplasm*/ tumor and the combined phrases for all genetic studies on the association between the cyclin D1 G870A polymorphism and GC risk. The reference lists of all articles were also manually screened for potential studies. Abstracts and citations were screened independently by two authors, all the agreed articles need a second screen for full-text reports. The searching was done without restriction on language.

\section{Selection and exclusion criteria}

Inclusion criteria: A study was included in this metaanalysis if it meet the following criteria: $i$ ) independent case-control studies for humans; $i i$ ) the study evaluated the association between cyclin D1 polymorphism and gastric cancer risk; iii) has available genotype frequencies in cancer cases and control subjects for risk estimate. We excluded comments, editorials, systematic reviews or studies lacking sufficient data. If the publications were duplicated or shared in more than one study, the most recent publications were included. All identified studies were screened by two investigators independently. What's more, there were no limitation for publication language.

\section{Data extraction and synthesis}

We used endnote bibliographic software to construct an electronic library of citations identified in the literature search. All the PubMed, EMBASE, Web of science and the Cochrane Library searches were performed using Endnote; duplicates were found automatically by endnote and deleted manually. All data extraction were checked and calculated twice according to the inclusion criteria listed above by two independent investigators. Data extracted from the included studies were as follows: First author, year of publication, country, ethnicity, Study design, Source of controls, Genotyping method and evidence of HWE in controls. A third reviewer would participate if some disagreements were emerged, and a final decision was made by the majority of the votes.

\section{Statistical analysis}

All statistical analyses were performed using STATA version 11.0 software (StataCorp LP, College Station, TX) and Review Manage version 5.2.0 (The Cochrane Collaboration, 2012). Hardy-Weinberg equilibrium (HWE) was assessed by $\chi^{2}$ test in the control group of each study [32]. The strength of associations between the cyclin D1 polymorphism and GC risk were measured by odds ratio (ORs) with 95\% confidence interval (CIs). Z test was used the to assess the significance of the ORs, $\mathrm{I}^{2}$ and $\mathrm{Q}$ statistics was used to determine the statistical heterogeneity among studies. A random-effect model was used if $\mathrm{P}$ value of heterogeneity tests was no more than $0.1(\mathrm{P} \leq 0.1)$, otherwise, a fixedeffect model was selected $[32,33]$. Sensitivity analyses were performed to assess the stability of the results. We used Begg's funnel plot and Egger's test to evaluate the publication bias $[34,35]$. The strength of the association was estimated in the allele model (A vs. G), the dominant model (AA + GA vs. GG), the recessive model (AA vs. GA $+\mathrm{GG}$ ), the homozygous genetic model (AA vs. GG), and the heterozygous genetic model (GA vs. GG), respectively. $P<0.05$ was considered statistically significant. We performed subgroup according to Ethnicity, Source of controls, Genotyping method, type of cancer, gender and $\mathrm{H}$. pylori infection.

\section{CONFLICTS OF INTEREST}

The authors have declared that no conflicts of interest exists.

\section{REFERENCES}

1. Nagini S. Carcinoma of the stomach: A review of epidemiology, pathogenesis, molecular genetics and chemoprevention. World journal of gastrointestinal oncology. 2012; 4:156-169. 
2. Torre LA, Bray F, Siegel RL, Ferlay J, Lortet-Tieulent J, Jemal A. Global cancer statistics, 2012. CA: a cancer journal for clinicians. 2015; 65:87-108.

3. Nicolas C, Sylvain M, Come L, Jean F, Anne-Marie B, Valerie J. Trends in gastric cancer incidence: a period and birth cohort analysis in a well-defined French population. Gastric cancer. 2015.

4. Morais S, Ferro A, Bastos A, Castro C, Lunet N, Peleteiro B. Trends in gastric cancer mortality and in the prevalence of Helicobacter pylori infection in Portugal. European journal of cancer prevention. 2015.

5. Kim HS, Lee H, Jeung HC, Noh SH, Chung HC, Roh JK, Nam CM, Rha SY. Advanced detection of recent changing trends in gastric cancer survival: up-to-date comparison by period analysis. Japanese journal of clinical oncology. 2011; 41:1344-1350.

6. Lin JT, Li HY, Chang NS, Lin CH, Chen YC, Lu PJ. WWOX suppresses prostate cancer cell progression through cyclin D1-mediated cell cycle arrest in the G1 phase. Cell cycle. 2015 ; 14:408-416.

7. Cai FF, Chen P, Chen L, Biskup E, Liu Y, Chen PC, Chang JF, Jiang WJ, Jing YY, Chen YW, Jin H, Chen S. Human RAD6 Promotes G1-S Transition and Cell Proliferation through Upregulation of Cyclin D1 Expression. Plos One. 2014; 9 .

8. Shih LC, Tsai CW, Tsai MH, Tsou YA, Chang WS, Li FJ, Lee MH, Bau DT. Association of cyclin D1 genotypes with nasopharyngeal carcinoma risk. Anticancer research. 2012; 32:1093-1098.

9. Tsai MH, Tsai CW, Tsou YA, Hua CH, Hsu CF, Bau DT. Significant association of cyclin D1 single nucleotide polymorphisms with oral cancer in taiwan. Anticancer research. 2011; 31:227-231.

10. Nagasawa S, Onda M, Sasajima K, Makino H, Yamashita K, Takubo K, Miyashita M. Cyclin D1 overexpression as a prognostic factor in patients with esophageal carcinoma. J Surg Oncol. 2001; 78:208-214.

11. Chen XM, Zhao TS, Li L, Xu CH, Zhang XL, Tse V, Zhang T, Liu XQ, Lu FM. CCND1 G870A Polymorphism with Altered Cyclin D1 Transcripts Expression Is Associated with the Risk of Glioma in a Chinese Population. DNA Cell Biol. 2012; 31:1107-1113.

12. Zhang J, Li Y, Wang R, Wen D, Sarbia M, Kuang G, Wu M, Wei L, He M, Zhang L, Wang S. Association of cyclin D1 (G870A) polymorphism with susceptibility to esophageal and gastric cardiac carcinoma in a northern Chinese population. International Journal of Cancer. 2003; 105:281-284.

13. Tahara T, Arisawa T, Shibata T, Yamashita H, Hirata I. Association between cyclin D1 (CCND1) polymorphism and gastric cancer risk in Japanese population. Hepatogastroenterology. 2009; 56:1232-1235.

14. Song JH, Kim CJ, Cho YG, Park YK, Nam SW, Yoo NJ, Lee JY, Park WS. Association of cyclin D1 G870A polymorphism with susceptibility to gastric cancers in Korean male patients. Neoplasma. 2007; 54:235-239.

15. Kuo W-H, Huang $\mathrm{C}-\mathrm{Y}, \mathrm{Fu} \mathrm{C}-\mathrm{K}$, Liao C-H, Hsieh Y-H, Hsu C-M, Tsai C-W, Chang W-S, Bau D-T. The Significant Association of CCND1 Genotypes with Gastric Cancer in Taiwan. Anticancer research. 2014; 34:4963-4968.

16. Kiel S, Geddert H, Gabbert HE, Sarbia M. Genetic polymorphism of p16INK4A and cyclin D1: relationship to disposition for the development of esophageal or gastric adenocarcinomas? Pathology Research and Practice. 2004; 200:314-315.

17. Jia A, Gong J, Li Y, Hao Z, Chang X, Dai F, Yu B. GG genotype of cyclin D1 G870A polymorphism is associated with non-cardiac gastric cancer in a high-risk region of China. Scandinavian journal of gastroenterology. 2008; 43:1353-1359.

18. Geddert H, Kiel S, Zotz RB, Zhang J, Willers R, Gabbert HE, Sarbia M. Polymorphism of p16INK4A and cyclin D1 in adenocarcinomas of the upper gastrointestinal tract. Journal of cancer research and clinical oncology. 2005; 131:803-808.

19. Fang X. Relation of cyclin D1 gene polymorphism and Helicobacter pylori infection to gastric cancer. Journal of Gastroenterology and Hepatology. 2013; 28:863.

20. Bukum E, Karkucak M, Duzgun A, Yakut T. Investigation of cyclin D1 (G870A) gene polymorphisms in patients with gastric carcinoma. Konuralp Tip Dergisi. 2013; $5: 18-22$.

21. Chen B, Cao L, Yang P, Zhou Y, Wu XT. Cyclin D1 (CCND1) G870A gene polymorphism is an ethnicitydependent risk factor for digestive tract cancers: A metaanalysis comprising 20,271 subjects. Cancer Epidemiology. 2012; 36:106-115.

22. Wainberg ZA, Yufa A, Anghel A, Rogers AM, Manivong T, Adhami S, Hamidi H, Conklin D, Finn RS, Slamon DJ. Expression of p16 in colon cancer and cyclin D1 in gastric cancer predicts response to CDK4/6 inhibition in vitro. Cancer Research. 2014; 74.

23. Zhang XM, Zhou CW, Gu H, Yan L, Zhang GY. Correlation of RKIP, STAT3 and cyclin D1 expression in pathogenesis of gastric cancer. Int J Clin Exp Patho. 2014; 7:5902-5908.

24. Betticher DC, Thatcher N, Altermatt HJ, Hoban P, Ryder WD, Heighway J. Alternate splicing produces a novel cyclin D1 transcript. Oncogene. 1995; 11:1005-1011.

25. Wu J, Wu SH, Bollig A, Thakur A, Liao DJ. Identification of the cyclin D1b mRNA variant in mouse. Mol Biol Rep. 2009; 36:953-957.

26. Hosokawa Y, Joh T, Maeda Y, Arnold A, Seto M. Cyclin D1/PRAD1/BCL-1 alternative transcript [B] protein product in B-lymphoid malignancies with $\mathrm{t}(11 ; 14)(\mathrm{q} 13 ; \mathrm{q} 32)$ translocation. International Journal of Cancer. 1999; 81:616-619. 
27. Hosokawa Y, Gadd M, Smith AP, Koerner FC, Schmidt EV, Arnold A. Cyclin D1 (PRAD1) alternative transcript b: Full-length cDNA cloning and expression in breast cancers. Cancer Lett. 1997; 113:123-130.

28. Lu FM, Gladden AB, Diehl JA. An alternatively spliced cyclin D1 isoform, cyclin D1b, is a nuclear oncogene. Cancer Research. 2003; 63:7056-7061.

29. Elliman SJ, Howley BV, Mehta DS, Fearnhead HO, Kemp DM, Barkley LR. Selective repression of the oncogene cyclin D1 by the tumor suppressor miR-206 in cancers. Oncogenesis. 2014; 3.

30. Chraybi M, Abd Alsamad I, Copie-Bergman C, Baia M, Andre J, Dumaz N, Ortonne N. Oncogene abnormalities in a series of primary melanomas of the sinonasal tract: NRAS mutations and cyclin D1 amplification are more frequent than KIT or BRAF mutations. Hum Pathol. 2013; 44:1902-1911.
31. Loh M, Koh KX, Yeo BH, Song CM, Chia KS, Zhu F, Yeoh KG, Hill J, Iacopetta B, Soong R. Meta-analysis of genetic polymorphisms and gastric cancer risk: Variability in associations according to race. European Journal of Cancer. 2009; 45:2562-2568.

32. Mantel N, Haenszel W. Statistical aspects of the analysis of data from retrospective studies of disease. Journal of the National Cancer Institute. 1959; 22:719-748.

33. DerSimonian R, Laird N. Meta-analysis in clinical trials. Controlled clinical trials. 1986; 7:177-188.

34. Begg CB, Mazumdar M. Operating characteristics of a rank correlation test for publication bias. Biometrics. 1994; 50:1088-1101.

35. Egger M, Davey Smith G, Schneider M, Minder C. Bias in meta-analysis detected by a simple, graphical test. Bmj. 1997; 315:629-634. 